Recebido em 06/2020. Aceito para publicação em 07/2020.

\title{
PREVALÊNCIA DE BACTÉRIAS MULTIRRESISTENTES NA CAVIDADE NASAL DE EQUINOS ASSINTOMÁTICOS PARA DOENÇAS RESPIRATÓRIAS
}

\section{PREVALENCE OF MULTIDRUG-RESISTANT BACTERIA IN THE NASAL CAVITY OF HORSES ASYMPTOMATIC FOR RESPIRATORY DISEASES}

\author{
Kedma Lorena da Silva Souza ${ }^{1}$ \\ João Vitor Stefanin Fuzatti ${ }^{2}$ \\ Richer Costa Camargo ${ }^{3}$ \\ Michel dos Santos Pinto 4 \\ Tainara Kossakowski Silva ${ }^{5}$ \\ Danila Fernanda Rodrigues Frias ${ }^{6}$
}

Resumo: O uso da antibioticoterapia em animais, na maioria das vezes, ocorre de maneira desorientada, o que colabora para o aumento da resistência microbiana. Neste contexto, o presente trabalho teve por objetivo avaliar a prevalência de bactérias multirresistentes na cavidade nasal de equinos assintomáticos para doenças respiratórias. Foram coletadas amostras de swab nasal de 50 equinos assintomáticos para doenças respiratórias. As amostras foram semeadas em placas de Petri contendo ágar sangue e ágar MacConkey, incubadas em aerobiose e microaerofilia a $37^{\circ} \mathrm{C}$ por 48 horas. As culturas puras foram submetidas à identificação segundo as características morfocoloniais, morfotintoriais e bioquímicofisiológicas convencionais. Também foi realizada a verificação da susceptibilidade antimicrobiana in vitro e em seguida calculado o índice de resistência múltipla. Das amostras analisadas foram isolados Staphylococcus aureus, Staphylococcus coagulase negativa, Streptococcus spp, Micrococcus spp, Enterobacter spp e Escherichia coli. O gênero Staphylococcus e Streptococcus demonstraram resistência total e intermediária a praticamente todos os antibióticos testados; o gênero Enterobacter aos $\beta$-lactâmicos, cefalosporinas, monobactam, quinolonas, anfenicóis, sulfozamidas, e aminoglicosídeos (amicacina e tobramicina); e E. coli aos $\beta$-lactâmicos, algumas cefalosporinas, monobactam, quinolonas, aminoglicosídeos, anfenicóis, sulfozamidas e tetraciclina. Todas as cepas analisadas apresentaram multirresistência. Conclui-se que equinos hígidos sem alteração respiratória, possuem microrganismos com potencial patogênico em suas fossas nasais. Além disso, o alto índice de resistência microbiana é preocupante e serve de alerta para o possível uso indiscriminado de antibióticos, o qual pode afetar a saúde animal e dos seres humanos.

Palavras-chave: Antibioticoterapia; multirresistência; resistência microbiana; saúde pública; equídeos.

Abstract: The application of antibiotic therapy in animals is mostly performed without orientation, which contributes to increasing microbial resistance. In this scenario, the present study was conducted to examine the prevalence of multidrug-resistant bacteria in the nasal cavity of horses asymptomatic for respiratory diseases. Nasal swab samples were collected from 50 horses asymptomatic for respiratory diseases. The samples were cultivated in Petri dishes containing blood agar and MacConkey agar, where they were incubated under aerobic and microaerophilic conditions at $37^{\circ} \mathrm{C}$ for $48 \mathrm{~h}$. Pure cultures were subjected to identification for conventional colony-morphological, staining-morphological and biochemical-physiological traits. In addition, in vitro antimicrobial susceptibility was tested and the multidrug resistance index was

\footnotetext{
1 Universidade Brasil, Brasil. E-mail: kedmalorenay@gmail.com.

2 Universidade Brasil, Brasil. E-mail: joaovitor_fuzati@hotmail.com.

3 Universidade Brasil, Brasil. E-mail: richercamargo69@gmail.com.

4 Universidade Brasil, Brasil. E-mail: michelsantos151@hotmail.com.

5 Universidade Brasil, Brasil. E-mail: tainarakossakowski@gmail.com.

6 Professor Titular Mestrado Ciências Ambientais, Universidade Brasil, Brasil. E-mail: danila.frias@universidadebrasil.edu.br.
} 
calculated. Staphylococcus aureus, coagulase-negative Staphylococcus, Streptococcus spp., Micrococcus spp., Enterobacter spp. and Escherichia coli were isolated from the analyzed samples. In terms of antimicrobial resistance, the genus Staphylococcus showed resistance to all of the antibiotics tested, except linezolid; the genus Streptococcus, to $\beta$-lactams, tetracyclines and glycopeptides; Enterobacter, to $\beta$ lactams, cephalosporins, monobactam, quinolones, amphenicols, sulfozamides and aminoglycosides (amicacine and tobramycin); and E. coli, to $\beta$-lactams, some cephalosporins, monobactam, quinolones, aminoglycosides, amphenicols, sulfonamides and tetracycline. All analyzed strains exhibited multidrug resistance. In conclusion, healthy horses without respiratory alterations have microorganisms with pathogenic potential in their nasal cavities. Additionally, the high level of microbial resistance is worrying and serves as a warning for the possible indiscriminate use of antibiotics, which can affect animal and human health.

Keywords: Antibiotic therapy; microbial resistance; multidrug resistance; public health; equidae.

\section{INTRODUÇÃO}

A utilização de antimicrobianos para tratamento e profilaxia de doenças infecciosas em animais e seres humanos ocorre mundialmente. Porém, na maioria das vezes, o seu uso não segue as recomendações, sendo feito de maneira desorientada. Desta forma, o uso incorreto, que ocorre principalmente em animais, colabora para o aumento da resistência antimicrobiana (ARIAS; MAIO CARRILHO, 2012).

A resistência antimicrobiana desenvolvida por meio do uso inadequado de antibióticos em animais é refletida também nos seres humanos, uma vez que, muitas classes desses medicamentos podem ser utilizadas para ambas as espécies. Sendo assim, é possível observar com maior frequência falhas terapêuticas que constituem grande risco à saúde animal e à saúde pública (ARIAS; MAIO CARRILHO, 2012).

O uso de antimicrobianos na medicina veterinária se faz necessário para o controle de doenças, a fim de garantir o bem estar animal. Além disso, auxilia na melhoria da produtividade, na prevenção da ocorrência de zoonoses, na promoção de crescimento, na redução de toxinfecções alimentares, entre outros fatores. Por isso, tais medicamentos são de extrema importância na prática desse segmento (BORBA, 2018).

Entre as principais enfermidades animais tratadas com antimicrobianos encontram-se as gastrintestinais, respiratórias, cutâneas e reprodutivas. Em equinos, salientam-se ainda as infecções musculoesqueléticas, oculares, além da profilaxia operatória (ROBINSON; SPRAYBERRY, 2009). Quando ocorre a resistência antimicrobiana de alguns destes agentes patogênicos causadores destas doenças, a seleção empírica dos antimicrobianos torna-se difícil, o que prejudica a eficiência do tratamento (SFACIOTTE et al., 2014).

Altas taxas de resistência a antimicrobianos já foram relatadas em isolados bacterianos provenientes de equinos, sendo as drogas mais resistentes nas cepas estudadas a penicilina, amoxacilina, ampicilina, estreptomicina, neomicina, tobramicina, eritromicina, clindamicina, rifampicina, tetraciclina, cefalotina, ceftriaxona, gentamicina, doxaciclina, sulfametoxazol, amoxacilina associado a ácido clavulônico, amicacina, azitromicina e cloranfenicol (SFACIOTTE et al., 2014). 
Nos hospitais veterinários existe o contato direto entre os animais e os seres humanos. Estudos sugerem que bactérias multirresistentes presentes no ambiente podem ser transmitidas aos seres humanos, principalmente por meio das mãos, vestimentas, fômites utilizados na rotina e, até mesmo por meio dos produtos animais e seus derivados. Dessa forma, a disseminação bacteriana ocorre entre estes dois grupos de maneira relevante (TORRES, 2019). Diante disso, o presente trabalho teve por objetivo avaliar a prevalência de bactérias multirresistentes na cavidade nasal de equinos assintomáticos para doenças respiratórias internados em ambiente hospitalar.

\section{METODOLOGIA}

A presente pesquisa foi desenvolvida no laboratório de Microbiologia da Universidade Brasil, Campus Fernandópolis, São Paulo. O projeto foi encaminhado ao Comitê de Ética para Uso de Animais (CEUA/Universidade Brasil) e o mesmo foi aprovado sob o n IC18-19/001.

Foram coletadas amostras de 50 equinos assintomáticos para doenças respiratórias, sendo estes sem raça definida e, com idade entre 12 e 24 meses, atendidos no Hospital Veterinário da Universidade Brasil, situado na cidade de Fernandópolis, São Paulo, entre os meses de maio a junho de 2019.

Os equinos utilizados para o estudo eram avaliados pelo médico veterinário responsável pelo setor, mediante realização de exame clínico completo. A partir disso, os animais que não possuíam nenhuma alteração respiratória eram selecionados para coleta de material para realização deste estudo.

O material foi colhido após prévia higienização da área com álcool $70 \%$, por meio da introdução de swab estéril que foi friccionado na mucosa de uma das narinas. As amostras foram colhidas em duplicata e acondicionadas em tubos de ensaio estéreis, levadas ao laboratório em caixa isotérmica e seguidas de processamento imediato.

Para realização da cultura, as amostras foram semeadas em placas de Petri contendo meio base de ágar sangue, acrescido de $10 \%$ de sangue de ovino desfibrinado e ágar MacConkey, incubadas em aerobiose e microaerofilia a $37^{\circ} \mathrm{C}$, em estufa bacteriológica por 48 horas.

Dado o período de incubação houve a obtenção de culturas puras, as quais foram submetidas à identificação preliminar segundo as características morfocoloniais e morfotintoriais. Posteriormente, cada grupo bacteriano foi identificado pelas características bioquímico-fisiológicas convencionais.

Após o isolamento e identificação bacteriana, foi realizada a verificação da susceptibilidade antimicrobiana in vitro por meio do método Kirby Bauer Modificado (BAUER et al., 1966). As colônias isoladas foram inoculadas em Agar Muller Hinton e incubadas por $24 \mathrm{~h}$ a $36^{\circ} \mathrm{C}$. Foram avaliados os seguintes antimicrobianos para bactérias 


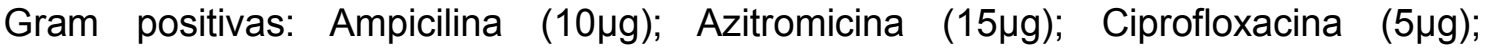
Clindamicina $(2 \mu \mathrm{g})$; Cloranfenicol $(30 \mu \mathrm{g})$; Eritromicina $(15 \mu \mathrm{g})$; Gentamicina $(10 \mu \mathrm{g})$; Oxacilina $(1 \mu \mathrm{g})$; Cefoxitina $(30 \mu \mathrm{g})$; Linezolida $(30 \mu \mathrm{g})$; Penicilina G $(10 \mu \mathrm{g})$; Rifampicina $(5 \mu \mathrm{g})$; Sulfazotrim $(25 \mu \mathrm{g})$; Tetraciclina $(30 \mu \mathrm{g})$ e Vancomicina $(30 \mu \mathrm{g})$;

Para bactérias Gram negativas: Ciprofloxacina $(5 \mu \mathrm{g})$, Gentamicina $(10 \mu \mathrm{g})$, Sulfametoxazol + Trimetoprim $(23,75 / 1,25 \mu \mathrm{g})$, Cloranfenicol $(30 \mu \mathrm{g})$, Ceftazidima (30 $\mu \mathrm{g})$, Ampicilina $(10 \mu \mathrm{g})$, Amicacina $(30 \mu \mathrm{g})$, Tobramicina $(10 \mu \mathrm{g})$, Tetraciclina $(30 \mu \mathrm{g})$, Ceftriaxona $(30 \mu \mathrm{g})$, Cefepime $(30 \mu \mathrm{g})$, Amoxicilina + Clavulanato $(10 \mu \mathrm{g})$, Aztreonam $(30 \mu \mathrm{g})$, Cefoxitina $(30 \mu \mathrm{g})$ e Cefotaxima $(30 \mu \mathrm{g})$.

Os halos de inibição de crescimento foram medidos e interpretados segundo parâmetros pré-estabelecidos do CLSI (CLSI, 2012). O cálculo do índice de resistência múltipla aos antimicrobianos (IRMA) foi realizado por meio da razão entre o número de antibióticos aos quais o isolado foi resistente e o número de antibióticos ao qual o isolado foi exposto. Quando o IRMA se encontra superior a 0.2, caracteriza-se a multirresistência (KRUMPERMAN, 1983).

\section{RESULTADOS E DISCUSSÃO}

Os resultados referentes às bactérias isoladas da cavidade nasal de equinos sem doença respiratória aparente, encontram-se na Tabela 1.

Tabela 1 - Distribuição da frequência dos microrganismos isolados das fossas nasais de equinos assintomáticos para doenças respiratórias internados em ambiente hospitalar, 2019.

Microrganismo

Staphylococcus aure
Staphylococcus coagulase
Streptococcus spp
Micrococcus spp
Enterobacter spp
Escherichia coli

Total Amostras Positivas

$\begin{array}{ll}42 & 84 \% \\ 28 & 56 \% \\ 12 & 24 \% \\ 26 & 52 \% \\ 12 & 24 \% \\ 10 & 20 \%\end{array}$

Fonte: Os autores.

A presença de microrganismos na cavidade nasal de equinos hígidos já foi descrita por outros autores, que citaram com maior frequência encontrar os gêneros Streptococcus spp, Staphylococcus spp, Actinobacillus sp, Bacillus sp, Escherichia coli, Proteus sp, Bordetella sp, Pseudomonas sp, Enterobacter spp, Klebsiella sp, Micrococcus $s p$, Nocardia $s p$, dentre outros (DARIEN et al., 1990; FERNANDES et al., 2011).

Bactérias do gênero Streptococcus spp, Staphylococcus spp e enterobacterias são microrganismos geralmente encontrados na nasofaringe dos equinos (DARIEN et al., 1990). Desta forma, quando avalia-se equinos hígidos, geralmente, todos os animais apresentam cultura positiva para pelo menos uma espécie bacteriana (DUARTE, 2007). 
De todos os animais avaliados, isolou-se pelo menos um gênero microbiano. Dentre eles, $83 \%$ eram cocos Gram positivos dos gêneros Staphylococcus, Streptococcus e Micrococcus, e 17\% Gram negativos, representados por Enterobacter spp e Escherichia coli. Estudo realizado por Duarte (2007), constatou que $40 \%$ dos microrganismos isolados de cavidade nasal de equinos sadios eram grupos de cocos Gram positivos dos gêneros Staphylococcus, Streptococcus, Enterococcus e Micrococcus, gêneros estes semelhantes aos encontrados neste estudo.

É importante salientar que alguns gêneros encontrados na atual pesquisa compreendem microrganismos frequentemente relatados como causadores de pneumonia em equinos, e podem provocar sérios danos à saúde humana (RACKLYEFT; LOVE, 2000).

Dentre os microrganismos isolados, o gênero Staphylococcus foi o de maior prevalência. Estes colonizam naturalmente os seres humanos e animais, podendo ser adquiridos logo após o nascimento e, manter a colonização por toda vida. Indivíduos imunossuprimidos, portadores de doenças crônicas, trabalhadores da área da saúde e animais, são os mais comuns portadores deste tipo de microrganismo. Vale ressaltar que esse gênero possui grande facilidade de disseminação em ambientes hospitalares por se adaptar às condições de sobrevivência neste local (CARTER et al., 2005; CAVALCANTI et al., 2006).

Em estudo realizado por Fernandes et al. (2011), o qual avaliou a microbiologia de lavados traqueobrônquicos de equinos clinicamente sadios, $35,3 \%$ dos animais avaliados também apresentaram o microrganismo Staphylococcus coagulase negativa. Assim como na pesquisa de Duarte (2007) que constatou a presença deste gênero em $16 \%$ das amostras analisadas.

Staphylococcus spp. também foram isolados de equinos com alterações morfofuncionais e portadores de infecções bacterianas e virais do trato respiratório anterior, de animais com broncopneumonia bacteriana e com obstrução recorrente das vias aéreas (FERNANDES et al., 2011). Além disso, já foi isolado de animais com processos pneumônicos com choque tóxico, abscessos pulmonares e botriomicoses pulmonares (MILLER et al., 2001; HOLBROOK et al., 2003). Este microrganismo é extremamente importante, pois pode provocar doenças nos seres humanos que podem apresentar desde uma infecção simples, como espinhas e furúnculos, até doenças graves, como pneumonia, meningite, endocardite, síndrome do choque tóxico e septicemia (SANTOS; MICHELOTTO-JÚNIOR; KOZEMJAKIN, 2007).

O segundo gênero de maior prevalência foi o Micrococcus. Este grupo geralmente é composto por agentes não patogênicos e que colaboram com o equilíbrio da microbiota natural local, raramente sendo percursores de casos de pneumonia. Este gênero já foi isolado em lavados traqueais de equinos sadios e de indivíduos com alterações morfofuncionais e portadores de infecções bacterianas e virais do trato respiratório anterior, com broncopneumonia bacteriana e com quadro alérgico 
(FERNANDES et al., 2011).

Outro gênero detectado nesta pesquisa foi o Streptococcus. Dentre os isolados neste trabalho, $72 \%$ eram Streptococcus $\beta$-hemolíticos e $28 \%$ Streptococcus $\alpha$ hemolíticos.

Pesquisa realizada por Duarte (2007), revelou a presença de Streptococcus $\beta$ hemolíticos e $\alpha$-hemolíticos em $7 \%$ das amostras avaliadas provenientes de equinos hígidos. Assim como na pesquisa de Fernandes et al. (2011) que detectaram a presença de Streptococcus $\beta$-hemolíticos e $\alpha$-hemolíticos em equinos sadios, com alterações morfofuncionais do trato respiratório anterior e em animais com broncopneumonia bacteriana, e apenas Streptococcus a-hemolíticos foram isolados de equinos com infecções bacterianas do trato respiratório anterior.

Streptococcus spp são facilmente isolados de mucosas do trato respiratório e em superfície corpórea de equinos, por isso, grande parte das infecções causadas por este gênero é oportunista (QUIN et al., 2019). Mesmo sendo encontrados na microbiota comum, eles representam riscos, pois possuem potencial patogênico para os pulmões (RACKLYEFT; LOVE, 2000). Equinos jovens, em início de treinamento, mesmo considerados clinicamente sadios, podem demonstrar algum tipo de distúrbio respiratório provocado por bactérias do gênero Streptococcus (SANTOS; MICHELOTTO-JÚNIOR; KOZEMJAKIN, 2007).

Este agente é patogênico e muito importante para a saúde pública pois pode causar faringite, pneumonia, sepse, endocardite e até meningite em seres humanos (BRAGA et al., 2008). Nos equinos, os Streptococcus $\beta$-hemolíticos são os microrganismos mais frequentemente isolados em casos de broncopneumonia e doença respiratória inflamatória (SILVA, 2011).

Com relação aos microrganismos Gram negativos encontrados nesta pesquisa, o gênero Enterobacter foi o de maior ocorrência. Este gênero também foi relatado no trabalho de Fernandes et al. (2011), que isolou este microrganismo de equinos sadios, portadores de infecções bacterianas do trato respiratório anterior e com obstrução recorrente das vias aéreas. Duarte (2007) também relatou que $21 \%$ dos animais sadios analisados possuíam este gênero bacteriano nas fossas nasais.

O gênero Enterobacter é comumente encontrado na traqueia e nasofaringe dos equídeos (DARIEN et al., 1990). Porém, de forma oportunista, pode ocasionar alterações pulmonares nos cavalos. Nos seres humanos, geralmente atuam também de forma oportunista principalmente em pessoas submetidas a antibioticoterapia, procedimentos invasivos e também portadores de doenças crônicas, como o diabetes (FERNANDES; VAZ FERNANDES; RIBEIRO FILHO, 2000)

Outro agente Gram negativo identificado nas fossas nasais de equinos sadios neste trabalho foi Escherichia coli. $\mathrm{O}$ isolamento desta bactéria de nasofaringe de equinos sadios já foi relatada por outros autores (DUARTE, 2007; FERNANDES et al., 
2011). Geralmente, este microrganismo está presente na traqueia de animais sadios e atua de forma oportunista, podendo desencadear quadros de pneumonias nos equinos (DARIEN et al., 1990).

Este patógeno também é encontrado no intestino de animais e seres humanos de forma comensal, porém, algumas cepas são patogênicas e devido aos diferentes mecanismos de virulência que possuem, eles podem causar diversas doenças nos animais e seres humanos (VERONESI; FOCACCIA, 2005; NAKAZATO et al., 2009).

Com relação a avaliação da susceptibilidade antimicrobiana dos agentes isolados nesta pesquisa, os resultados referentes ao gênero Staphylococcus estão descritos na Tabela 2.

Tabela 2 - Susceptibilidade antimicrobiana do gênero Staphylococcus isolados de fossas nasais de equinos assintomáticos para doenças respiratórias internados em ambiente hospitalar, 2019.

\begin{tabular}{|c|c|c|c|}
\hline ANTIBIÓTICO & RESISTENTE & INTERMEDIÁRIO & SUSCEPTÍVEL \\
\hline Ampicilina $(10 \mu g)$ & $100 \%$ & - & - \\
\hline Oxacilina $(1 \mu g)$ & $100 \%$ & - & - \\
\hline Penicilina G $(10 \mu g)$ & $100 \%$ & - & - \\
\hline Cefoxitina $(30 \mu g)$ & $100 \%$ & - & - \\
\hline Azitromicina $(15 \mu \mathrm{g})$ & $68,75 \%$ & $6,25 \%$ & $25 \%$ \\
\hline Eritromicina $(15 \mu g)$ & $31,25 \%$ & $68,75 \%$ & - \\
\hline Ciprofloxacina $(5 \mu g)$ & $81,25 \%$ & $6,25 \%$ & $12,5 \%$ \\
\hline Clindamicina $(2 \mu g)$ & $100 \%$ & - & - \\
\hline Cloranfenicol $(30 \mu g)$ & $50 \%$ & $12,5 \%$ & $37,5 \%$ \\
\hline Gentamicina $(10 \mu \mathrm{g})$ & $75 \%$ & $25 \%$ & - \\
\hline Linezolida $(30 \mu g)$ & $25 \%$ & - & $75 \%$ \\
\hline Rifampicina $(5 \mu g)$ & $31,25 \%$ & $31,25 \%$ & $37,5 \%$ \\
\hline Sulfazotrim $(25 \mu g)$ & $37,5 \%$ & $18,75 \%$ & $43,75 \%$ \\
\hline Tetraciclina $(30 \mu g)$ & $75 \%$ & $18,75 \%$ & $3,75 \%$ \\
\hline
\end{tabular}

Pode-se observar que o gênero Staphylococcus demonstrou resistência total e intermediária a praticamente todos os antibióticos testados. Fato este que pode estar relacionado a grande capacidade de desenvolvimento de resistência a antibióticos que o microrganismo possui (KLEVENS et al., 2006). Além disso, este microrganismo é muito importante para a saúde pública e os equinos podem possuir este patógeno com elevado grau de resistência a antibióticos e transmiti-los facilmente aos seres humanos (WEESE et al., 2006).

Avaliando a classe dos antibióticos testados, notou-se $100 \%$ das cepas isoladas apresentaram resistência aos $\beta$-lactâmicos. Estes antibióticos foram muito utilizados para o combate do gênero Staphylococcus durante muito tempo, desta forma, devido a pressão exercida sobre estes microrganismos por estes fármacos, o aparecimento de resistência ocorreu de forma precoce (LLARRULL; FISHER; MOBASHERY, 2009). A alta 
resistência aos $\beta$-lactâmicos por microrganismos do gênero Staphylococcus já foi relatada por vários autores, corroborando esta pesquisa (COSTA et al., 2012; FARIÑA et al., 2013; NOEL et al., 2016; CASTELLANO-GONZALEZ et al., 2018).

De acordo com Sawant, Gillespie e Oliver (2009), a oxacilina pode ser utilizada como padrão de interpretação de resistência do gênero Staphylococcus a meticilina, e segundo o CLSI (2012), os resultados obtidos para sensibilidade a oxacilina podem ser extrapolados aos outros $\beta$-lactâmicos. Desta forma, nesta pesquisa, todas as amostras apresentaram resistência a oxacilina, podendo então ser consideradas todas resistentes a meticilina e aos demais $\beta$-lactâmicos.

Staphylococcus resistentes a meticilina é o patógeno de maior prevalência em hospitais, e notou-se nos últimos anos, aumento relevante de casos de infecções comunitárias por este patógeno (MARCO, 2004). Esta informação é muito importante, pois atualmente ocorreu o aumento do isolamento de cepas de Staphylococcus spp. resistentes a meticilina associadas a resistência a outros antibióticos, como a eritromicina, tetraciclina, aminoglicosídeos, quinolonas e cloranfenicol, o que dificulta o tratamento de afecções provocadas por este microrganismo (CASTELLANOGONZALEZ et al., 2018).

Outros grupos de antibióticos que apresentaram taxas elevadas de resistência (acima de $75 \%$ ) neste estudo foram os macrolídeos, quinolonas, lincosaminas, aminoglicosídeos e tetraciclinas. Outras pesquisas também demonstraram taxas elevadas de resistência antimicrobiana de Staphylococcus spp, como Gade; Qazi (2013) que relataram $92,5 \%$ de resistência a quinolonas, Noel et al. (2016) detectaram 57\% de resistência a quinolonas, $56 \%$ a tetraciclinas, $17,9 \%$ a macrolídeos e $14,9 \%$ a aminoglicosídeos, assim como Silva (2012) constatou $18 \%$ de resistência a aminoglicosídeos.

Com relação aos anfenicóis (cloranfenicol), ansamicinas (rifampicina) e sulfozamidas, esta pesquisa revelou resistência total e intermediária em mais de $50 \%$ dos Staphylococcus spp. isolados. Morales; Yaneth; Chávez (2012) relataram resistência ao cloranfenicol de $30,8 \%$ das amostras de Staphylococcus spp isoladas, e Oliveira (2019), 12,5\% das amostras. Já Perazzi et al. (2012) encontraram apenas 10\% dos Staphylococcus spp. resistentes a rifampicina, enquanto Oliveira (2019) detectou $12,5 \%$ dos isolados resistentes a rifampicina, e nenhum a sulfozamidas.

O antibiótico que apresentou melhor eficácia foi a Linezolida (75\%). Carvalho et al. (2019) também relataram em sua pesquisa $100 \%$ das amostras de Staphylococcus spp sensíveis a Linezolida. Já, estudo realizado por Castellano-Gonzalez et al. (2018) revelou sensibilidade maior frente aos aminoglicosídeos, diferindo dos dados encontrados neste trabalho.

Quando analisado o IRMA, notou-se que todas as estirpes de microrganismos do gênero Staphylococcus apresentaram multirresistência, com média de IRMA 0.65 
(mínimo 0.35, máximo 0.85). Carvalho et al. (2019) também constataram multirresistência dos isolados de Staphylococcus spp analisados em sua pesquisa. Assim como Mesquita et al. (2019) que isolou este gênero bacteriano e encontrou IRMA médio de 0.31 (0.0 a 0.76).

O perfil de multirresistência encontrado neste trabalho é preocupante devido à gravidade a saúde pública, pois os equinos demonstraram ser portadores de Staphylococcus spp multirresistentes tornando-se reservatórios e fontes de transmissão ao ser humano, tanto em ambientes hospitalares, como em manejos diários realizados pelos tratadores e tutores destes animais.

$\mathrm{Na}$ Tabela 3 estão descritos os resultados referentes a susceptibilidade antimicrobiana dos isolados do gênero Streptococcus.

Tabela 3 - Susceptibilidade antimicrobiana do gênero Streptococcus isolados de fossas nasais de equinos assintomáticos para doenças respiratórias internados em ambiente hospitalar,

\begin{tabular}{|c|c|c|c|}
\hline ANTIBIÓTICO & RESISTENTE & INTERMEDIÁRIO & SUSCEPTÍVEL \\
\hline Ampicilina $(10 \mu g)$ & $100 \%$ & - & - \\
\hline Penicilina G $(10 \mu g)$ & $100 \%$ & - & - \\
\hline Azitromicina $(15 \mu g)$ & $66,8 \%$ & $16,6 \%$ & $16,6 \%$ \\
\hline Eritromicina $(15 \mu g)$ & $66,8 \%$ & $16,6 \%$ & $16,6 \%$ \\
\hline Clindamicina $(2 \mu g)$ & $83,4 \%$ & - & $16,6 \%$ \\
\hline Cloranfenicol $(30 \mu g)$ & $83,4 \%$ & $16,6 \%$ & - \\
\hline Linezolida $(30 \mu g)$ & $83,4 \%$ & - & $16,6 \%$ \\
\hline Rifampicina $(5 \mu g)$ & $83,4 \%$ & - & $16,6 \%$ \\
\hline Tetraciclina $(30 \mu g)$ & $100 \%$ & - & - \\
\hline Sulfazotrim $(25 \mu \mathrm{g})$ & $83,4 \%$ & $16,6 \%$ & - \\
\hline Vancomicina $(30 \mu g)$ & $100 \%$ & - & - \\
\hline
\end{tabular}

Pode-se observar que o gênero Streptococcus isolados de fossas nasais de equinos hígidos demonstrou elevado grau de resistência (acima de 60\%) a todos os antibióticos avaliados.

Para a classe dos $\beta$-lactâmicos, tetraciclinas e glicopeptídeos, as cepas isoladas foram $100 \%$ resistentes. As licosaminas, anfenicóis, oxazolidinonas, sulfozamidas e ansamicinas testadas apresentaram acima de $80 \%$ de resistência. Mesquita et al. (2019) relataram elevada resistência (próximo a 100\%) frente à $\beta$-lactâmicos, licosaminas e aminoglicosídeos. Assim como Pansani et al. (2016) descreveram resistência de $63 \%$ à tetraciclina e Manzoor et al. (2008) sugeriu índice de 100\% de resistência à tetraciclina.

Os macrolídeos apresentaram elevada resistência total e intermediária na atual pesquisa, assim como no trabalho de Silva (2015), que relataram a elevada resistência aos macrolídeos e também as tetraciclinas.

Neste estudo, dentre os antibióticos testados, não foi encontrado eficiência contra 
o gênero Streptococcus. Já na pesquisa de Mesquita et al. (2019), mostrou-se efetivos os anfenicóis (florfenicol) e sulfozamidas (sulfazotrim).

Ao analisar o IRMA, todas as estirpes de microrganismos do gênero Streptococcus testadas apresentaram multirresistência, com IRMA variando de 0.7 a 1.0 (média 0.93). Mesquita et al. (2019) encontraram em sua pesquisa IRMA médio de 0.62 com variação de 0.19 a 0.90 .

$\mathrm{Na}$ Tabela 4 estão descritos os resultados referentes a susceptibilidade antimicrobiana das cepas isoladas do gênero Enterobacter.

Tabela 4 - Susceptibilidade antimicrobiana do gênero Enterobacter isolados de fossas nasais de equinos assintomáticos para doenças respiratórias internados em ambiente hospitalar, 2019.

ANTIBIÓTICO

Ampicilina $(10 \mu \mathrm{g})$
Amoxicilina + Clavulanato $(30 \mu \mathrm{g})$
Ceftazidima $(30 \mu \mathrm{g})$
Cefepime $(30 \mu \mathrm{g})$
Cefotaxima $(30 \mu \mathrm{g})$
Cefoxitina $(30 \mu \mathrm{g})$
Ceftriaxona $(30 \mu \mathrm{g})$
Aztreonam $(30 \mu \mathrm{g})$
Ciprofloxacina $(5 \mu \mathrm{g})$
Amicacina $(30 \mu \mathrm{g})$
Tobramicina $(10 \mu \mathrm{g})$
Gentamicina $(10 \mu \mathrm{g})$
Cloranfenicol $(30 \mu \mathrm{g})$
Sulfametoxazol + Trimetoprim
(23,75/1,25 $2 \mathrm{~g})$
Tetraciclina $(30 \mu \mathrm{g})$

RESISTENTE
SUSCEPTÍVEL

\begin{tabular}{|ccc}
\hline $100 \%$ & - & - \\
$66,7 \%$ & - & $33,3 \%$ \\
$66,7 \%$ & - & $33,3 \%$ \\
$66,7 \%$ & - & $33,3 \%$ \\
$100 \%$ & - & - \\
$100 \%$ & - & - \\
$33,3 \%$ & $33,3 \%$ & $33,4 \%$ \\
$33,3 \%$ & $66,7 \%$ & - \\
$66,7 \%$ & $33,3 \%$ & - \\
- & $66,7 \%$ & $33,3 \%$ \\
$33,3 \%$ & $33,3 \%$ & $33,4 \%$ \\
- & - & $100 \%$ \\
$33,3 \%$ & $33,3 \%$ & $33,4 \%$ \\
$66,7 \%$ & - & $33,3 \%$ \\
& - & $66,7 \%$ \\
$33,3 \%$ & - &
\end{tabular}

Todas as amostras isoladas do gênero Enterobacter apresentaram resistência total ou intermediária (acima de $60 \%$ ) para os $\beta$-lactâmicos, cefalosporinas, monobactam, quinolonas, anfenicóis, sulfozamidas, e alguns exemplares de aminoglicosídeos (amicanina e tobramicina). Em pesquisa realizada por Braga (2011), o gênero Enterobacter apresentou resistência elevada as cefalosporinas, assim como no trabalho de Soares et al. (2016). Monteiro; Zyban; Sidat (2011), e Soares et al. (2017), detectaram resistência frente aos $\beta$-lactâmicos. Todas as cepas isoladas do gênero Enterobacter apresentou multirresistência com IRMA de 0.53 a 0.86 (média 0.66).

Os antibióticos que demonstraram eficácia as cepas do gênero Enterobacter isoladas foram a gentamicina (100\%), e tetraciclina (66,7\%). Estes dados diferem dos citados por Lima; Veiga (2018), que detectaram eficácia das fluoroquinolonas (ciprofloxacina e norfloxacina), porém Pinheiro, Coitinho e Stopiglia (2017) afirmou a 
sensibilidade de Enterobacter spp a gentamicina.

Com relação aos resultados referentes a resistência antimicrobiana de $E$. coli isoladas das amostras analisadas nesta pesquisa, os dados estão expostos na Tabela 5.

Tabela 5 - Susceptibilidade antimicrobiana de E. coli isolados de fossas nasais de equinos assintomáticos para doenças respiratórias internados em ambiente hospitalar, 2019.

\begin{tabular}{|c|c|c|c|}
\hline ANTIBIÓTICO & RESISTENTE & INTERMEDIÁRIO & SUSCEPTÍVEL \\
\hline Ampicilina $(10 \mu g)$ & $66,7 \%$ & $33,3 \%$ & - \\
\hline Amoxicilina + Clavulanato $(30 \mu g)$ & $66,7 \%$ & $33,3 \%$ & - \\
\hline Ceftazidima $(30 \mu g)$ & $33,3 \%$ & $66,7 \%$ & - \\
\hline Cefepime $(30 \mu g)$ & - & - & $100 \%$ \\
\hline Cefotaxima $(30 \mu g)$ & - & $100 \%$ & - \\
\hline Cefoxitina $(30 \mu g)$ & $33,3 \%$ & $33,3 \%$ & $33,4 \%$ \\
\hline Ceftriaxona $(30 \mu g)$ & - & - & $100 \%$ \\
\hline Aztreonam $(30 \mu g)$ & $33,3 \%$ & $33,3 \%$ & $33,4 \%$ \\
\hline Ciprofloxacina $(5 \mu g)$ & $33,3 \%$ & $33,3 \%$ & $33,4 \%$ \\
\hline Amicacina $(30 \mu g)$ & - & $100 \%$ & - \\
\hline Tobramicina $(10 \mu g)$ & $33,3 \%$ & $33,3 \%$ & $33,4 \%$ \\
\hline Gentamicina $(10 \mu g)$ & $66,7 \%$ & $33,3 \%$ & - \\
\hline Cloranfenicol $(30 \mu \mathrm{g})$ & $66,7 \%$ & $33,3 \%$ & - \\
\hline $\begin{array}{c}\text { Sulfametoxazol + Trimetoprim } \\
(23,75 / 1,25 \mu \mathrm{g})\end{array}$ & $66,7 \%$ & - & $33,3 \%$ \\
\hline Tetraciclina $(30 \mu g)$ & $66,7 \%$ & $33,3 \%$ & - \\
\hline
\end{tabular}

E. coli apresentou resistência total e intermediária aos $\beta$-lactâmicos, algumas cefalosporinas, monobactam, quinolonas, aminoglicosídeos, anfenicóis, sulfozamidas e tetraciclina. Mota; Oliveira; Souto (2018) relataram resistência de E. coli entre $50 \%$ a $70 \%$ para ampicilina e ciprofloxacina, $30 \%$ a $40 \%$ para ácido nalidíxico, trimetropim/sulfametoxazol, norfloxacina, cefuroxima, ceftriaxona, cefepime e cefalotina. Carneiro et al. (2017), também confirmaram resistência para amicacina, ceftiofur, cefatoxime, ciprofloxacina e gentamicina.

De acordo com a Organização Mundial da Saúde, E. coli está classificada como prioridade crítica de resistência, por isso existe a necessidade urgente de produção de novos antibióticos (WHO, 2017).

Apresentaram efeito inibitório contra E. coli duas cefalosporinas (Cefepime e Ceftriaxona). Em pesquisa realizada por Gonçalves et al. (2019) foi detectada sensibilidade a cefaloxina e ciprofloxacina, assim como no estudo de Mota; Oliveira; Souto (2018) que relataram sensibilidade a cefoxitina, ceftazidimina e gentamicina, dados estes que diferiram deste estudo.

Todas as estirpes de E. coli avaliadas apresentaram multirresistência com IRMA 
de 0.6 a 0.73 (média 0.66). Carneiro et al. (2017) relataram $8 \%$ das cepas de $E$. coli isoladas multirresistentes, enquanto Schoster et al. (2012) detectaram 2,6\%, e Clark et al. (2008), não encontraram cepas de E. coli multirresistentes. Dados semelhantes ao desta pesquisa foi relatado por Mota; Oliveira; Souto (2018) que informaram a elevada multirresistência de estirpes de E. coli avaliadas.

Todos os microrganismos discutidos neste trabalho foram isolados de equinos hígidos, que são manejados pelos tratadores, proprietários e neste caso, por funcionários do hospital veterinário. Deste modo, cuidados com o manejo dos animais é imprescindível, pois estes patógenos podem causar danos à saúde humana. Além disso, os resultados são preocupantes devido ao elevado índice de resistência múltipla bacteriana aos antibióticos testados.

Um estudo realizado em um centro cirúrgico veterinário revelou presença de bactérias multirresistentes Gram-positivas e Gram-negativas que foram responsáveis por provocar infecções hospitalares da mesma forma que ocorre na medicina humana (AIELLO et al., 2007). Por isso o cuidado em manejar os animais é imprescindível.

Muitos microrganismos podem permanecer no ambiente mesmo após a desinfecção e serem veiculados pelos profissionais, em suas mãos, luvas, vestimentas, equipamentos (FERREIRA et al., 2015). Além disso, muitos trabalhadores estão em contato constante com indivíduos colonizados por bactérias multirresistentes, onde podem se transformar em reservatórios e disseminadores destes patógenos, e também adquirir resistência aos antimicrobianos utilizados para o combate a estes microrganismos (FRACAROLI; OLIVEIRA; MARZIALE, 2017).

Para evitar este tipo de problema, medidas de proteção devem ser executadas por meio do uso de equipamentos de proteção individual (EPIs) adequado a prática laboral exercida. Dentre os EPIs podemos citar o uso de luvas, máscaras, avental e óculos de proteção como obrigatórios na manipulação de pacientes que possuam microrganismos multirresistentes (BRASIL, 1978). Como neste estudo foi encontrado microrganismos multirresistentes em indivíduos sadios, deve-se sempre fazer uso de EPIs ao manipular qualquer animal.

Outra questão importante é o reconhecimento do profissional de saúde em relação a problemática da resistência aos antimicrobianos, e que sua solução requer esforços de vários segmentos, como os médicos, veterinários, produtores, farmacêuticos (UMBER; BENDER, 2009). Desta forma, deve-se entender a epidemiologia dos patógenos, aliado a interação ser humano e animal e o uso correto dos antibióticos em todas as espécies (WEESE; DUIJKEREN, 2010).

\section{CONCLUSÃO}

Com a realização deste trabalho pode-se concluir que, mesmo em equinos hígidos e sem alteração respiratória, isolou-se microrganismos com potencial patogênico de 
suas fossas nasais, Gram negativos e Gram positivos, com destaque para o gênero Staphylococcus, Streptococcus e Enterobacter. Portanto, durante a manipulação dos animais, existe o risco eminente de transmissão destes patógenos aos seres humanos. Desta forma, é extremamente necessário a utilização de EPIs pelos responsáveis em manipular animais visando a prevenção do contágio.

Além disso, o alto índice de resistência microbiana é preocupante e serve de alerta para o possível uso indiscriminado de antibióticos, o qual pode resultar em graves falhas de tratamento, afetando diretamente a saúde animal e dos seres humanos.

\section{AGRADECIMENTOS}

Agradecemos ao CNPq pela concessão da bolsa e a Universidade Brasil pela disponibilização do laboratório de microbiologia e hospital veterinário.

\section{REFERÊNCIAS}

AIELLO, G. et al. Determinação dos índices de infecção hospitalar em um centro cirúrgico universitário veterinário de pequenos animais. Acta Scientiae Veterinariae, v. 35, n. 2, p. 354s-356s, 2007.

ARIAS, M. V. B.; MAIO CARRILHO, C. M. D. Resistência antimicrobiana nos animais e no ser humano. Há motivo para preocupação? Semina: Ciências Agrárias, v. 33, n. 2, p. 775-790, 2012.

BAUER, A.W. et al. Antibiotic susceptibility testing by a standardized single disk method. American Journal Clinical Pathology, v. 45, n. 4, p. 493-496, 1966.

BORBA, M. R. Resistência a antimicrobianos criticamente importantes à saúde humana em populações bacterianas de animais de produção criados no Brasil, 2008 a 2017. 2018. 43 f. Trabalho de conclusão de curso (Especialização) Universidade Federal do Rio Grande do Sul, Porto Alegre, 2018.

BRAGA, A.C.P.V. et al. Boas práticas. 2008. Disponível em: http://www.anvisa.gov.br/servicosaude/controle/rede_rm/cursos/boas_praticas/modulo4 lobjetivos.htm. Acesso em: 20 mar. 2020.

BRAGA, I. A. Úlcera por pressão como reservatório e fonte de infecção por bacilos gram-negativos em pacientes internados em um hospital de nível terciário e em residentes de instituições de longa permanência para idosos. 2011. 93f. Mestrado (Dissertação) - Universidade Federal de Uberlândia, Uberlândia, 2011.

BRASIL. Ministério do Trabalho e Emprego. Secretaria de Inspeção do Trabalho. Portaria N. ${ }^{\circ} 3.214,08$ de junho de 1978. "Aprova as Normas Regulamentadoras - NR do Capítulo V, Título II, da Consolidação das Leis do Trabalho, relativas à Segurança e Medicina do Trabalho". Diário Oficial, Brasília,1978. 
CARNEIRO, V.C. et al. Virulence, resistance, and genetic relatedness of Escherichia coli and Klebsiella sp. isolated from mule foals. Arq. Bras. Med. Vet. Zootec. v. 69, n. 5, p. 1073-1082, 2017.

CARTER, M. E. et al. Microbiologia veterinária e doenças infecciosas. Porto Alegre: Artimed, 2005.

CARVALHO, L.C.A. et al. Ocorrência de Staphylococcus spp. resistente à meticilina em otite externa canina. RBAC, v. 51, n. 4, p. 342-347, 2019.

CASTELLANO-GONZALEZ, M. et al. Frecuencia y resistencia antimicrobiana en Staphylococcus. Kasmera, v. 46, n. 1, p. 26-39, 2018.

CAVALCANTI, S. M. M. et al. Estudo comparativo de Staphylococcus aureus importado para as unidades de terapia intensiva de hospital universitário, Pernambuco, Brasil. Rev. Bras. Epid., v. 9, n. 4, p. 436-446, 2006.

CLARK, C. et al. Bacterial isolates from equine infections in western Canada (19982003). Can. Vet. J. v. 49, n. 2, p. 153-160, 2008.

CLSI. Clinical and Laboratory Standards Institute. Performance standards for antimicrobial susceptibility testing. Twenty-second Informational Suplement M100s22, Wayne, v. 32, n. 3, p. 1-184, 2012.

COSTA, G.M. et al. Population diversity of Staphylococcus aureus isolated from bovine mastitis in Brazilian dairy herds. J. Research in Veterinary Science, v. 93, n. 2, p. 733-735, 2012.

DARIEN, B. J. et al. Tracheoscopic techique for obtaining uncontaminated lower airway secretions for bacterial culture in the horse. Equine Veterinary Journal, v. 22, n. 3, p. 170-173, 1990.

DUARTE, R. R. Perfil bacteriológico de biópsia pulmonar e lavado traqueobrônquico de equinos sadios mantidos em sistema extensivo e estabulado. 2007. 102f. Dissertação (Mestrado) - Universidade Estadual Paulista, Botucatu, 2007.

FARIÑA, N. et al. Staphylococcus coagulasa-negativa clínicamente significativos: Especies más frecuentes y factores de virulencia. Rev. Chil. Infectol. v. 30, n. 5, p. 480-488, 2013.

FERNANDES, A. T.; VAZ FERNANDES, M. O.; RIBEIRO FILHO, N. Infecção hospitalar e suas interfaces na área da saúde. 2. ed. São Paulo: Atheneu, 2000.

FERNANDES, W. R. et al. Achados microbiológicos do lavado traqueobrônquico de equinos clinicamente sadios e daqueles portadores de afecções do sistema respiratório atendidos no HOVET, USP. ARS Veterinaria, v. 27, n. 2, p. 73-79, 2011.

FERREIRA, A. M. et al. Avaliação da desinfecção de superfícies hospitalares por diferentes métodos de monitoramento. Rev. Latino- Am. Enfermagem, v. 23, n. 3, p. 466-474, 2015.

FRACAROLLI, I.F.L.; OLIVEIRA, A.S.; MARZIALE, M.H.P. Colonização bacteriana e resistência antimicrobiana em trabalhadores de saúde: revisão integrativa. Acta Paulista de Enfermagem, v. 30, n. 6, p. 651-7, 2017. 
GADE, N.; QAZI, M. Fluoroquinolone Therapy in Staphylococcus aureus Infections: Where Do We Stand? J Lab Physicians, v. 5, n. 2, p. 109-112, 2013.

GONÇALVES, S. et al. Perfil de resistência a antibióticos de Escherichia coli produtorase não produtoras da toxina shiga. In: SIMPÓSIO INIAV PARAA SEGURANÇA ALIMENTAR RUMO À ALIMENTAÇÃO DO FUTURO, 1., 2019. Anais..., Portugal, 2019.

HOLBROOK, T. C. et al. Toxic shock syndrome in a horse with Staphylococcus aureus pneumonia. J. Am.Vet. Med. Assoc, v. 222, n. 5, p. 620-623, 2003.

KLEVENS, M. et al. Staphylococcus aureus resistente a meticilina asociado a la comunidad y factores de riesgos para la salud. Emerg Infect Dis, v. 12, n. 12, p. 1991-1993, 2006.

KRUMPERMAN, P. H. Multiple Antibiotic Resistance Indexing of Escherichia coli to Identify High-Risk Sources of Fecal Contamination of Foods. Applied and Environmental Microbiology, v. 46, n. 1, p. 165-170, 1983.

LIMA, J.K.S.; VEIGA, W.A. Identificação das bactérias responsáveis pelas ITU e seu perfil de resistência aos principais fármacos utilizados no tratamento. Revista Interdisciplinar do Pensamento Científico, v. 4, n. 3, p. 426-432, 2018.

LLARRULL, L.; FISHER, J.; MOBASHERY, S. Molecular Basis and Phenotype of Methicillin Resistance in Staphylococcus aureus and Insights into New $\beta$-Lactams That Meet the Challenge. Antimicrob Agents Chemother, v. 53, n. 10, p. 4051-4063, 2009.

MANZOOR, S. et al. Occurrence of Lancefiel group C streptococcal species in strangles cases of foals in Punjab, Pakistan. Pakistan Veterinary Journal, v. 8, n. 1, p. 17-20, 2008.

MARCO, F. Infección por Staphylococcus aureus resistente a la meticilina. Gastroenterol Hepatol Contin. v. 3, n. 3, p. 134-137, 2004.

MESQUITA, A.A. et al. Prevalence and antibiotic resistance of Staphylococcus aureus and Streptococcus agalactiae in family-owned dairy herds in the state of Minas Gerais, Brazil. Vet. Not., v. 25, n. 2, p. 186-205, 2019.

MILLER, M. A. et al. Pulmonary botryomycosis in a Scottish highland steer. J. Vet. Diagn. Invest. v. 13, n. 1, p. 74-6, 2001.

MONTEIRO, L.G.; ZYBAN, T.F.; SIDAT, M.M. Padrão de sensibilidade aos antimicrobianos de enterobacteriaceae isoladas no hospital central de Maputo, Moçambique 2009-2010. Rev Cient. UEM: Série Ciênc Bioméd Saúde Pública, v. 1, n. 1, p. 7- 13, 2015.

MORALES, G.; YANETH, M.; CHÁVEZ, K. Caracterización de la resistencia in vitro a diferentes antimicrobianos en cepas de Staphylococcus spp. en una institución hospitalaria de la ciudad de Valledupar entre enero y julio de 2009. Rev. Cienc. Salud., v.1 0, n. 2, p. 5-13, 2012.

MOTA, F.S.; OLIVEIRA, H.Á.; SOUTO, R.C.F. Perfil e prevalência de resistência aos antimicrobianos de bactérias Gram-negativas isoladas de pacientes de uma unidade de terapia intensiva. RBAC, v. 50, n. 3, p. 270-277, 2018. 
NAKAZATO. G. et al. Virulence factors of avian pathogenic Escherichia coli (APEC). Pesquisa Veterinária Brasileira, v. 29, n. 7, p. 479-486, 2009.

NOEL, C.C. et al. Perfil de suscetibilidade antimicrobiana e produção de "slime" de isolados de Staphylococcus spp. provenientes de casos de mastite bovina na região sul-fluminense. Revista de Saúde, v. 7, n. 1, p. 22-26, 2016.

OLIVEIRA, S. N. Prevalência de Staphylococcus aureus em jalecos de graduandos e profissionais da saúde na Universidade Federal de Uberlândia. 2019. 29f.Trabalho de Conclusão de Curso (Graduação) - Universidade Federal de Uberlândia. Uberlândia, 2019.

PANSANI, A.M. et al. Prevalência e resistência a antibióticos de (Streptococcus equi) da cavidade nasal de equinos hígidos no município de Fernandópolis, São Paulo, Brasil. Acta Veterinaria Brasilica, v. 10, n. 2, p. 144-149, 2016.

PERAZZI, B. et al. Staphylococcus aureus: nuevos y antiguos antimicrobianos. Rev Argent Microbiol.; v. 42, n. 3, p. 199-202, 2012.

PINHEIRO, T.R.; COITINHO, G.N.; STOPIGLIA, C.D.O. Perfil de sensibilidade de enterobactérias isoladas de carne bovina comercializadas na cidade de Uruguaiana. In: SALÃO INTERNACIONAL DE ENSINO, PESQUISA E EXTENSÃO - SIEPE, 9., 2017. Anais..., Santana do Livramento, 2017. p. 1-7.

QUIN, P. J. et al. Microbiologia Veterinária Essencial. 2 ed. Porto Alegre: Artmed, 2019.

RACKLYEFT, D. J.; LOVE, D. N. Bacterial infection of the lower repiratory tract in 34 horses. Australian Veterinary Journal, v. 78, n. 8, p. 549-559, 2000.

ROBINSON, N. E.; SPRAYBERRY, K. A. Current therapy in equine medicine. 6. ed. St Louis: Saunders Elsevier, 2009.

SANTOS, L.C.P.; MICHELOTTO-JÚNIOR, P.V.; KOZEMJAKIN, D.A. Achados endoscópico e citológico das vias respiratórias de potros puro sangue inglês em início de treinamento no Jóquei Clube do Paraná. Arquivos de Ciências Veterinárias e Zoologia Unipar, v. 10, n. 1, p. 9-13, 2007.

SAWANT, A.A.; GILLESPIE, B.E.; OLIVER, S.P. Antimicrobial susceptibility of coagulase-negative Staphylococcus species isolated from bovine milk. Veterinary Microbiology, v. 134, n. 1-2, p. 73-81, 2009.

SCHOSTER, A. et al. Longitudinal study of Clostridium difficile and antimicrobial susceptibility of Escherichia coli in healthy horses in a community setting. Vet. Microbiol, v. 159, p. 364-370, 2012.

SFACIOTTE, R. A. P. et al. Descrição de cepas bacterianas multirresistentes isoladas de equinos. Revista de Ciências Veterinárias e Saúde Pública, v. 1, supl. 1, 2014.

SILVA, E. R. Perfil de sensibilidade antimicrobiana in vitro de Staphylococcus aureus isolado de mastite subclínica bovina. Revista Brasileira de Saúde e Produção Animal, v. 13, n. 3, p. 701-711, 2012.

SILVA, J. R. Avaliação da virulência e susceptibilidade a antibióticos em 
Streptococcus agalactiae isolados de mastite bovina de rebanhos brasileiros. 2015. 83f. Dissertação (Mestrado) - Universidade Federal de Lavras, Lavras, 2015.

SILVA, N. A. A lavagem traqueal e a lavagem broncoalveolar como métodos de diagnóstico da doença respiratória em equinos. 2011. $117 \mathrm{f}$. Tese (Doutorado) Universidade Técnica de Lisboa, Lisboa, 2011.

SOARES, G.G. et al. Biofilm production and resistance profile of Enterobacter sp. strains isolated from pressure ulcers in Petrolina, Pernambuco, Brazil. J Bras Patol Med Lab. v. 52, n. 5, p. 293-298, 2016.

SOARES, J.H.R. et al. Identificação microbiológica e perfil de resistência a antimicrobianos em crianças hospitalizadas. Rev. Soc. Bras. Enferm. Ped. v. 17, n. 2, p. 57-63, 2017.

TORRES, M.C. Resistência antimicrobiana em populações animais e seu impacto na saúde pública: uma revisão da literatura. 2019. 48f. Trabalho de conclusão de curso (Graduação) - Universidade Federal do Rio Grande do Sul, Porto Alegre, 2019.

UMBER, J.K.; BENDER, J.B. Pets and antimicrobial resistance. Veterinary Clinics North America. Small Animal Practice, v.39, n.2, p.279-292, 2009.

VERONESI, R.; FOCACCIA, R. Tratado de Infectologia. Rio de Janeiro: Atheneu; 2005.

WEESE, J. S. et al. Methicillin-resistant Staphylococcus aureus in horses at a veterinary teaching hospital: frequency, characterization, and association with clinical disease. J. Vet. Intern. Med. v. 20, n. 1, p. 182-186, 2006.

WEESE, J.S.; VAN DUIJKEREN, E. Methicillin resistant Staphylococcus aureus and Staphylococcus pseudointermedius in veterinary medicine. Veterinary Microbiology, v. 140, n. 3, p. 418-429, 2010.

WORLD HEALTH ORGANIZATION (WHO). Global priority list of antibioticresistant bacteria to guide research, discovery, and development of new antibiotics, p. 1-7, 2017. 